\title{
A New Term Starts
}

James Yoder

I

am very pleased to take over as President of The Oceanography Society. While serving as President-elect, I was impressed with Ken Brink's leadership and efforts to build and improve our society. On behalf of the TOS members I thank Ken for the great job he did the past two years. In the current political vernacular, we are in better shape now than two years ago! Two examples. Next year, we have an exciting meeting planned for 2-5 April 2001, in Miami. One of our goals for this meeting, and why we chose this venue, is to encourage closer relations between ocean science and ocean technology. In response to membership comments, we adjusted the meeting format to allow more contributed oral presentations, yet we kept the popular TOS meeting features, including the plenary sessions. Furthermore, TOS members will not be charged a meeting registration fee and will have access to the large Oceanology International (OI) exhibition. Second, I believe that Rick Spinrad has moved our journal, Oceanograply, into an important and much needed niche. As you have probably noticed, most of our recent issues including this one are primarily dedicated to an important theme or subject area in oceanography. These focused and very readable articles help to educate our readers on many of the new and important interdisciplinary developments in our field. This is an important contribution in what is rapidly becoming the "information overload" age to many of us, as we struggle to keep up with the scientific literature.

My top priority for the next two years is to make sure that TOS contributes to the new and exciting developments in oceanography and marine science. For example, the Oceans Act recently passed by Congress and signed by the President will help focus U.S. national attention on ocean science, policy and management and set the new administration's national agenda for growth in these areas. The newly formed House Oceans Caucus will operate in parallel to help inform the Congress on ocean issues. These are but two examples of new initiatives whose participants need information from the broader oceanographic community to make intelligent decisions and to set priorities that will affect our careers in the future. TOS and Oceanography are well placed to provide some of the key information, and we need to make sure that we have a quality product and a strong organization.

To strengthen TOS, we need to continue publishing a high quality journal. One of our goals for the next two years is to increase publication from 3 to 4 issues per year, with perhaps the additional issue dedicated to unsolicited articles. We are also actively investigating web publication options for the journal or for individual articles. The TOS Council will continue to explore options for our biennial scientific meeting. We may continue with OI, or we may try other options. However, one option we will NOT try during my term as President is to schedule scientific sessions over busy weekends during the holiday season! We also want to increase our membership, both regular and student, and you will hear from me if you forget to return your renewal. We also want more corporate/institutional sponsors, and this will be one of my priorities for the exhibition hall during the April meeting. With these and other initiatives, I hope that in 2 years that I too will leave a stronger organization than I inherited.

I look forward to the next two years. I hope you enjoy this issue of Oceanography.

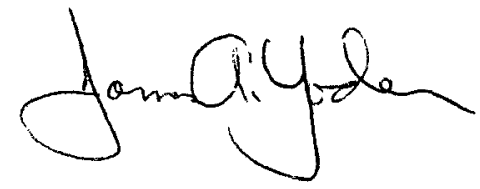

Ocearography (ISSN 1042-8275) is published by The Oceanography Society, 5912 LeMay Road, Rockville, MD 20851 USA. (C) 2000, The Oceanography Society, Inc. All rights reserved. Permission is granted to copy an article in this publication for use in teaching or research. For more extensive copying, a fee of $\$ 1.00$ per article can be paid through the Copyright Clearance Center, 21 Congress Street, Salem, MA 01970. Republication, systemic reproduction, or collective redistribution of any material in this publication is permitted only with the approval of The Oceanography Society. Send change-of-address information to the Society address. Postmaster: Bulk mail postage paid Suburban, MD; Permit 3905. 